\title{
Comprehensive benefit evaluation for port container transportation based on Malmquist index and cluster analysis
}

\author{
Yuyan $\mathrm{He}^{1, \mathrm{a}}$, Zhigao Liao ${ }^{1, \mathrm{~b}^{*}}$ and Liying Huang ${ }^{1, \mathrm{c}}$ \\ ${ }^{1}$ School of management, Guangxi University of science and technology ,Guangxi Liuzhou 545006, \\ China \\ a80.angel.2008@163.com, 'liaozhigao@126.com, 649357012@qq.com
}

Keywords: The expected output; Comprehensive benefit evaluation; Malmquist index; Cluster analysis; Container transportation

\begin{abstract}
The paper regards the port container transportation as object, the unexpected output as input variables, using Malmquist model to calculate 12 ports comprehensive benefit in 2009-2014. Meanwhile, the paper will use cluster analysis to analyze influencing 12 ports' specific factors of comprehensive benefit. The result shows that the comprehensive benefit of Qingdao is very high, technology level and scale efficiency of the Beibu Gulf less than 1.
\end{abstract}

\section{Introduction}

With CO2 emissions increasing severely, it has become the focus of world to decrease "carbon emissions". The relevant literature studies have shown that the main factors of CO2 emissions are transportation. According to Commerce Department statistics, in 2013 China and the "Silk Road economic belt" countries in total trade amounted to 600 billion US dollars, accounting for 15.5 percent of China's total foreign trade. Therefore, port container rail transports not only develop green transportation system with its low-cost and environmentally friendly advantages, but also develop regional economy and industry. Driven "one belt one road" policy, each port container rail transport rapidly developing, how to evaluate comprehensive benefits with scientific and reasonable method has becoming important. Besides, it is significant for us to understand the development characteristics of China Port Container rail transport, energy conservation policy and ultimately achieve low-carbon development.

Z.H. Jin (2011) [1] established a comprehensive index system and made an empirical analysis from Shandong Peninsula to Korea by fuzzy grey matter-element. X.F. Fu (2011) [2] identified the all impacts of container multimodal transport logistics safety indicators based on three levels of scaling law analysis model. H.S. Pu (2013) [3] built standards-based evaluation index system to investigate comprehensive evaluation steps and models combined with AHP, fuzzy theory and DEA. H.L. Yang (2011) [4]combined factor analysis and cluster analysis to get the Hebei agricultural logistics capabilities score ranking by SPSS18.0 to evaluate regional agricultural logistics capability. X.M. Deng (2014) [5] built 3 class regional logistics development level to evaluate system based on factor analysis and cluster analysis and took nine cities in the Pearl River Delta as an example. Y. Xiang (2015) [6] use fuzzy clustering analysis to obtain the logistics industry, where first echelon high levels; second develop stably and the third and fourth backward.

The above is mostly used in a single method, while most empirical studies are based on static analysis and research on container rail transport comprehensive benefit evaluation is not much. This paper taking quantitative data, it's more objectively true and the result is more reliable. Taking into account the low-carbon factors, the undesirable output are processed as input variables, in the form 
of contrast, the paper uses Malmquist method to evaluate comprehensive benefits of the Beibu Gulf container rail transport after considering environmental variables.

\section{Malmquist Index Theory}

Fare (1994) established the Malmquist index, which is an important indicator of changes in total factor productivity. As a non-parametric frontier efficiency analysis method, due to its more significant advantages, it is currently widely used.

Let and are inputs and outputs of the Relationship between $t$ and $t+1$ period, to change from input-output relationship is productivity change, change is not only from the technical level of productivity change, but also from changes in technical efficiency. For the distance function, based Malmquist productivity index $\mathrm{t}$ and $\mathrm{t}+1$ light of developments technology are as follows:

$$
M_{t}\left(x^{t}, y^{t}, x^{t+1}, y^{t+1}\right)=\frac{D_{c}^{t}\left(x^{t+1}, y^{t+1}\right)}{D_{c}^{t}\left(x^{t}, y^{t}\right)} M_{t+1}\left(x^{t}, y^{t}, x^{t+1}, y^{t+1}\right)=\frac{D_{c}^{t+1}\left(x^{t+1}, y^{t+1}\right)}{D_{c}^{t+1}\left(x^{t}, y^{t}\right)}
$$

The economic implications of the above index are symmetrical. In accordance with the ideal exponent, we define their geometric integrated productivity index:

$$
M\left(x^{t}, y^{t}, x^{t+1}, y^{t+1}\right)=\left(M_{t} \times M_{t+1}\right)^{1 / 2}=\left[\frac{D_{c}^{t}\left(x^{t+1}, y^{t+1}\right)}{D_{c}^{t}\left(x^{t}, y^{t}\right)} \frac{D_{c}^{t+1}\left(x^{t+1}, y^{t+1}\right)}{D_{c}^{t+1}\left(x^{t}, y^{t}\right)}\right]^{1 / 2}
$$

On the problem of decomposition of comprehensive productivity index, we use the RD model (Ray and Desli decomposition). The results are as follows[7-8]:

$$
\begin{aligned}
& M\left(x^{t}, y^{t}, x^{t+1}, y^{t+1}\right)=\frac{D_{v}^{t+1}\left(x^{t+1}, y^{t+1}\right)}{D_{V}^{t}\left(x^{t}, y^{t}\right)} \times\left[\frac{D_{V}^{t}\left(x^{t}, y^{t}\right)}{D_{V}^{t+1}\left(x^{t}, y^{t}\right)} \frac{D_{V}^{t}\left(x^{t+1}, y^{t+1}\right)}{D_{V}^{t+1}\left(x^{t+1}, y^{t+1}\right)}\right]^{1 / 2} \\
& \times\left[\frac{D_{c}^{t}\left(x^{t+1}, y^{t+1}\right) / D_{V}^{t}\left(x^{t+1}, y^{t+1}\right)}{D_{c}^{t}\left(x^{t}, y^{t}\right) / D_{V}^{t}\left(x^{t}, y^{t}\right)} \frac{D_{c}^{t+1}\left(x^{t+1}, y^{t+1}\right) / D_{V}^{t+1}\left(x^{t+1}, y^{t+1}\right)}{D_{c}^{t+1}\left(x^{t}, y^{t}\right) / D_{V}^{t+1}\left(x^{t}, y^{t}\right)}\right]^{1 / 2}
\end{aligned}
$$

Especially, TFP can be decomposed into pure technical efficiency and the overall efficiency, namely $\mathrm{TFP}=$ effch $\times$ tech. Overall efficiency values can be decomposed into pure technical efficiency and scale efficiency changes, namely effch=pech $\times$ sech.TFP is the total factor productivity index, reflecting the decision unit productivity development which relys on their own management, the improvement level and technology. Effch is comprehensive efficiency value changes, indicating that investment in certain circumstances obtains the maximum output capability. Tech, technical changes, in the production of mobile frontier reflects the extent of the productivity change contribution.

\section{Empirical Research}

Index Selection and Data Sources. Learned from the results of previous summary, input and output indicators are as follows in Table 1. Input indicators include infrastructure investment and energy consumption. Infrastructure investment is the ability to provide enterprises basic needs which was used in the production as intermediate inputs, while provided investment services and other basic facilities for improving an unfavorable external environment for the community. Energy consumption intensity refers to energy consumption per unit of output in a country or region within a certain time. Energy consumption is formula is the product of the port freight volume and freight energy consumption coefficient. These data come from ports statistical yearbook in 2009--2014. 
Output indicators include the sea-rail intermodal logistics volume, foreign trade volume and CO2 emissions. This paper replaces the sea-rail intermodal logistics volume with freight turnover referenced Z.N. Song (2011). The total amount of foreign trade is a representation of all the country's foreign trade in a given period, including imports and exports. The data comes from ports statistical yearbook in 2009--2014. CO2 emissions refer to the amount of greenhouse gas emissions per unit of goods accumulated. At the same time, data collection are difficulty, while we will reference to X.H. Liu (2014) proposed master's thesis.

Table 1 Port Container rail transport Comprehensive benefit evaluation input-output index selection

\begin{tabular}{cccc}
\hline Index type & index & variables & references \\
\hline input & infrastructure investments & X1 & C.Y. Cui, 2011; Q.H. Zhang 2010; W. Wang 2010 \\
input & energy source exhaustion & X2 & J. Huang 2011; T. Lan 2014; N. Sun 2014 \\
output & logistics volume & Y1 & H.Y. Yang 2011; X.Y. Mao 2013;Y.T. Ma 2014 \\
output & foreign trade volume & Y2 & G.W. Yan 2010; Y.Q. Chen 2010; H.R. Wu 2012 \\
unexpected output & $\mathrm{CO}_{2}$ emissions & Y3 & N. Sun 2014; R.J. Sun 2012; X.Y. Mao 2013 \\
\hline
\end{tabular}

The Empirical Results and Explanations. Taking into account the undesirable output, during 2009-2014(Table 2), the rail transport of containers TFP index is lower than not considering undesirable output. However, TFP $\geq 1.000$ indicating TFP container rail transport is still a positive contribution to economic growth, especially a positive stimulus after considering low-carbon factors. Therefore, the $\mathrm{CO} 2$ emissions are not taken into account the comprehensive benefits.

After considering low-carbon factors, China's technological level of container rail transport is greater than 1, which is considered as the main source, indicating that the forefront technology have relatively strong positive effect on TFP. Most scale efficiency is less than 1, indicating that technical efficiency in general has a negative impact on TFP Pure technical efficiency decreased, meaning that technological innovation may not spread to the community through the correct channels from Table 2, TFP of Dalian, Shanghai, Ningbo, Nanjing, Xiamen, Shenzhen, Guangzhou and the Beibu Gulf are reduced, and Dalian, Ningbo, Xiamen, Shenzhen, TFP value Guangzhou and North Bay are less than 1, where TFP was in the "bad" state, which decreases the economic development of these provinces and the overall efficiency of the rail transport of containers. Scale efficiency value of Qingdao, Tianjin, and the Beibu Gulf increase, mainly due to increasing skill levels. The low efficiency of resource was used by the Beibu Gulf container rail transport. 
Table 2 TFP comparison with not considering unexpected output and considering unexpected output

\begin{tabular}{cllllllllll}
\hline & \multicolumn{4}{c}{ not considering expected TFP output } & \multicolumn{5}{c}{ considering expected TFP output } \\
\hline districts & TFP & effch & tech & pech & sech & TFP & effch & tech & pech & sech \\
DaLian & 1.004 & 1.014 & 0.990 & 1.000 & 1.014 & 0.999 & 0.998 & 1.001 & 1.001 & 0.997 \\
QingDao & 1.042 & 1.032 & 1.009 & 1.002 & 1.030 & 1.145 & 1.059 & 1.082 & 1.001 & 1.057 \\
TianJin & 0.919 & 0.955 & 0.963 & 1.000 & 0.955 & 1.037 & 1.020 & 1.016 & 1.000 & 1.020 \\
ShangHai & 1.063 & 1.059 & 1.003 & 1.000 & 1.059 & 1.001 & 0.998 & 1.004 & 1.000 & 0.998 \\
NingBo & 1.115 & 1.067 & 1.044 & 1.011 & 1.055 & 0.999 & 1.012 & 0.987 & 1.004 & 1.008 \\
LianYunGulf & 0.972 & 1.000 & 0.972 & 1.000 & 1.000 & 1.010 & 1.000 & 1.010 & 1.000 & 1.000 \\
NanJing & 1.014 & 1.000 & 1.014 & 1.000 & 1.000 & 1.000 & 0.999 & 1.001 & 1.003 & 0.997 \\
XiaMen & 1.006 & 1.004 & 1.002 & 1.014 & 0.990 & 0.989 & 0.983 & 1.006 & 1.002 & 0.981 \\
ShenZhen & 1.069 & 1.000 & 1.069 & 1.000 & 1.000 & 0.927 & 1.000 & 0.927 & 1.000 & 1.000 \\
GuangZhou & 0.999 & 1.054 & 0.948 & 1.005 & 1.049 & 0.972 & 0.975 & 0.996 & 1.000 & 0.975 \\
HaiKou & 0.981 & 1.025 & 0.957 & 1.028 & 0.997 & 1.015 & 0.996 & 1.019 & 1.014 & 0.982 \\
BeiBuGulf & 0.965 & 0.976 & 0.989 & 1.015 & 0.962 & 0.928 & 0.961 & 0.966 & 0.991 & 0.970 \\
avarage & 1.011 & 1.015 & 0.996 & 1.006 & 1.009 & 1.000 & 1.000 & 1.001 & 1.001 & 0.998 \\
\hline
\end{tabular}

Cluster Analysis. To further analyze the TFP characteristics of various ports of container rail transport, the paper uses spss19.0 software to analyze TFP after considering undesirable output. In order to avoid collinearity between the variables affecting the result, the paper regards the technology change level, pure technical efficiency and scale efficiency changes as variable system clustering. After normalization, the results were shown in Fig. 1.

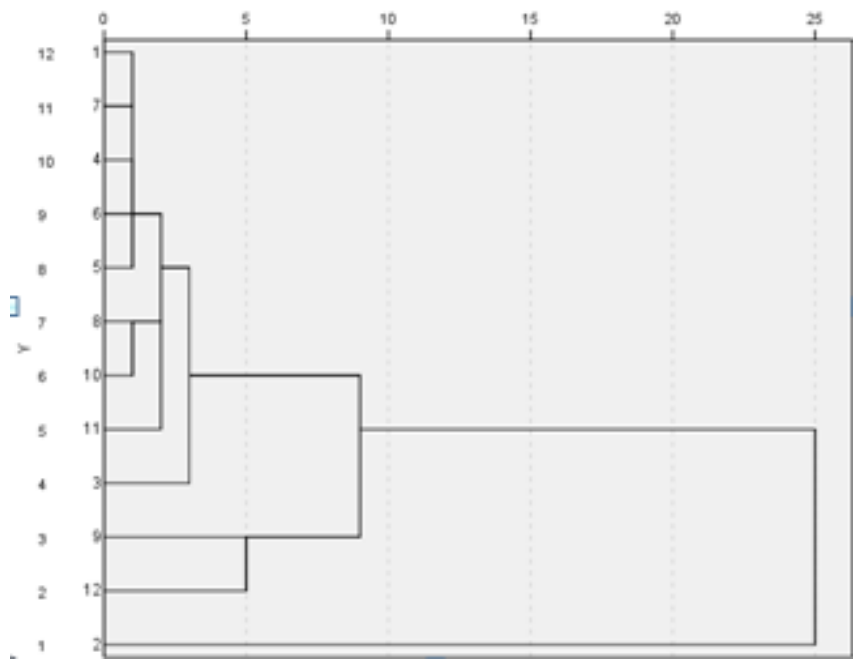

Figure 1. 12 Ports Container rail transport Comprehensive Benefit cluster diagram

According to Fig. 1, these ports were classified three echelons. The first echelon, pure technical efficiency of 9 ports is greater than 1, indicating that a high level of technology can improve the overall efficiency of the rail container transport by technological means. TFP value, from the point of view, Tianjin, Shanghai, Lianyungang, Nanjing and Haikou is greater than 1, indicating a high overall efficiency and an overall increasing economic trend. Overall efficiency of value only in Tianjin, Ningbo and Lianyungang is greater than 1, indicating that even the impact of low-carbon factors, technical level and extent of application of these three ports are still very high. 
The second echelon, technical level、pure technical efficiency and scale efficiency of Qingdao are greater than 1. The contribution of TFP highlighted, indicates that low-carbon factors make the technical level and extent of the application quickly improved, promoting scientific input-output growth and a high overall efficiency of value.

The third tier, the technique level of the Beibu Gulf and Shenzhen Gulf is less than 1, indicating that the technology is in outdated state, causing the entire economy declining. The Beibu Gulf is rather special and its geographical location and level of economic development have led to its relatively low level of technology and scale efficiency. Compared with the first-two echelon, the recession becomes more apparent. Inputs and outputs in Guangxi have not been used reasonably and need to attract the relevant attention of the government.

\section{Conclusions and Recommendations}

From the input-output point of view, we can see that after considering undesirable output, Qingdao Port technical efficiency, technical level and TFP are greater than 1. Beibu Gulf and Shenzhen Gulf technological level, especially technical efficiency, technological level and overall efficiency of the Beibu Gulf less than 1, shows that input doesn't reasonable output and comprehensive benefits.

In order to improve the resources utilization efficiency, the paper proposes some advices. Firstly, considering low-carbon factors all ports should be adjusted to adapt to each port's infrastructure investment and energy consumption to improve economy scale and ultimately improve the overall efficiency. Then, developing port container rail transport based on low-carbon perspective not only need improve the technical level and increase research funding, but also improve the use of efficient technologies. Last, government intervention may be appropriate.

\section{Acknowledgements}

The study is subsidized by the Project of Guangxi Philosophy and Social Science Fund (No. 13BGL009), the teaching reform project in higher education of Guangxi (No. 2012JGA178) and Countermeasures Research of Management Ability Promotion Based on Data Mining Technology (2013JD013).

\section{References}

[1] Z.H.Jin, Q.Xu, M.Chen, Evaluation and empirical research of Container Intermodal channel, Chinese scientific papers line, (2011)90-394.

[2] X.F. Fu, H.L. Wang, J. Zhang, evaluation of intermodal container logistics security based on Three - mark Method, logistics technology, (2011)85-86 + 135 .

[3] H.S. Pu, H.B. Liu, B. Zhang, comprehensive evaluation OF Container Intermodal interoperability, Chinese sailing, (2013)125-129.

[4] H.L. Yang, L. Yang, Factor Cluster Analysis in regional agricultural logistics capability evaluation - in Hebei Province, Chinese Agricultural Science Bulletin, (2011)128-132.

[5] X.M. Deng, S.J.Ma, comprehensive evaluation of the Pearl River Delta regional logistics development based on factors and cluster analysis, Wuyi University (Natural Science), (2014)21-27. 
[6] Y. Xiang, Y. Li, evaluation the logistics industry of the Jiangsu Province development based on fuzzy clustering analysis, Logistics Technology, (2015)85-88.

[7] Y. Zhang, H. Sun, compare 9 provinces TFP of "Silk Road economic belt" based on DEA-Malmquist index method, Social Sciences in Xinjiang, (2015)15-22 + 161.

[8] G.Y. YANG, Y.H. Zheng, Measurement of Evaluation of considering undesirable output efficiency of regional economic development, Statistics and Decision, (2013)146-149.

[9] Y. J. Guo, comprehensive evaluation theory, methods and applications, Science Press, Publishing Inc, Bei Jing, 2007,pp.55-83.

[10]Z. X. Ma, data envelopment analysis model and method, Science Press, Publishing Inc, Bei Jing, 2010,pp.76-155. 